\title{
It's never too late- spontaneous rupture of spleen and life-threatening hypovolemic shock in a patient recuperating from legionnaire's disease
}

\author{
Naveen Yadav ${ }^{1}$, Krishnaswamy Sundararajan ${ }^{1}$
}

\section{Abstract}

Spontaneous non-traumatic rupture of the spleen in the setting of Legionnaires' disease is very uncommon but a life-threatening condition. The splenic rupture can present within a few days after symptom onset with significant hypotension with drop in haemoglobin along with left side upper quadrant pain. Most of the cases described in the previous literature have presented within 0-11 (mean 4) days of the pneumonia but this case we are reporting presented after 3 weeks after being treated with Legionella pneumonia. The case also highlights an atypical presentation and emphasises the need to maintain a low threshold for diagnosis especially in resource constrained setting so that patient can be transferred at the earliest to a centre where appropriate corrective measures including surgery can be safely undertaken.

Keywords: splenic rupture, pneumonia, hypovolemic shock

Introduction

Spontaneous non-traumatic rupture of the spleen is extremely rare. However, there is potential for this complication to be lifethreatening in hematological, inflammatory, infective, and neoplastic diseases. There has been documentation of the multisystem involvement in Legionnaire's diseases [1]. However, pneumonia seems to be the most common and vital manifestation of the infection with Legionella [2]. Spontaneous rupture of the spleen has been very rarely seen with pneumonia, with only a few cases caused by Legionella [3-5]. Domingo et al. offered a broad review on the spontaneous rupture of the spleen, covering Legionella and other pathogens [5]. This case highlights the importance of having a high index of clinical suspicion about this complication even a few weeks post recovery from Legionnaires' disease.

\section{Case Report}

A 69-year-old male presented to our hospital after being transferred from one of the rural hospital where he presented following a collapse on the floor, and he denied any history of major or minor trauma, hematemesis or melena. No history of altered sensorium. His blood pressure on presentation in the rural ED was 75/50 $\mathrm{mmHg}$, heart rate of $120 / \mathrm{min}$, and haemoglobin was $99 \mathrm{~g} / \mathrm{l}$ on venous blood gs which showed a $\mathrm{pH}$ of 7.20 and a lactate of 2.4 $\mathrm{mmol} / \mathrm{L}$. His respiratory rate was $24 /$ minute and $\mathrm{SpO}_{2}$ of $97 \%$ on room air. This patient had been transferred to this rural hospital only two weeks after ten days of admission in our hospital following right lower lobe legionella pneumonia. (Fig. 2) He had successfully undergone rehabilitation in rural hospital and was discharged home. On this admission, he was noted to be anxious, agitated, pale and had a moist skin with cool, clammy extremities keeping in with an acute vasoconstricted profile and with mild oliguria. Since the above mentioned features in keeping with hypovolemic shock, he was being actively resuscitated. Along those lines, as it happens in Australia with wide geographical separation between treatment centres, the rural hospital contacted our hospital, which happens to be the quaternary referral centre for Central Australia for transfer through the retrieval team. When the retrieval team reached the rural hospital, he was found be severely compromised from a circulation point of view and needed intubation and commencement of multi-system organ supports. There was sudden onset abdominal pain with a precipitous drop in haemoglobin from $99 \mathrm{~g} / \mathrm{l}$ to $50 \mathrm{~g} / \mathrm{l}$. The abdominal examination revealed tender left upper quadrant. The working diagnosis at that moment was of septic shock in a patient who had recovered from Legionella pneumonia. The other differentials of isolated left sided abdominal pain like cardiac ischemia, pulmonary embolism, perforated duodenum, and sigmoid diverticulitis and acute severe pancreatitis were ruled out. The rural team did not find any evidence of the above differentials on bloods and chest X-ray. The team at rural hospital did not consider doing an ultrasound of the abdomen as it is relatively uncommon to consider splenic rupture

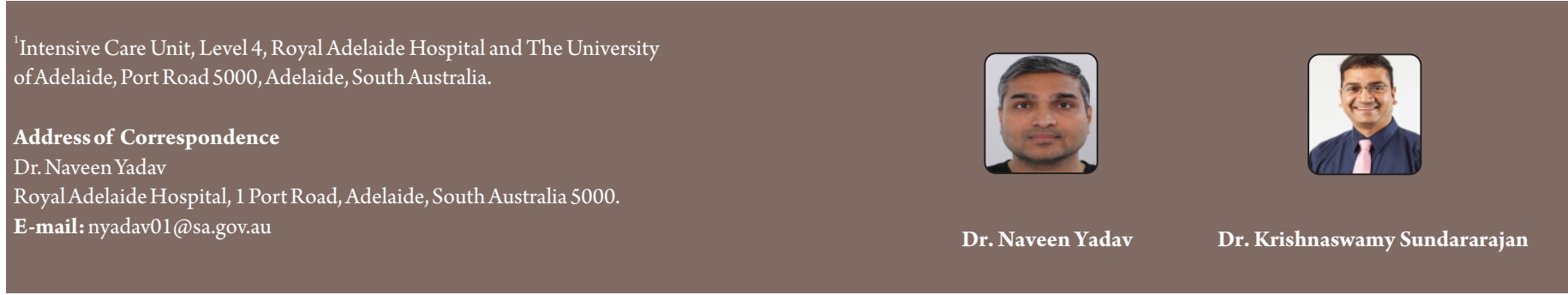

Submitted: 11 February 2021; Reviewed: 18 March 2021; Accepted: 2 April 2021; Published: 10 May 2021

DOI: 10.13107/jaccr.2021.v07i02.173

This is an Open Access article distributed under the terms of the Creative Commons Attribution Non-Commercial-Share Alike 4.0 License (http://creativecommons.org/licenses/by-nc-sa/4.0) which allows others to remix, tweak, and build upon the work non-commercially as long as appropriate credit is given and the new creation are licensed under the identical terms. 


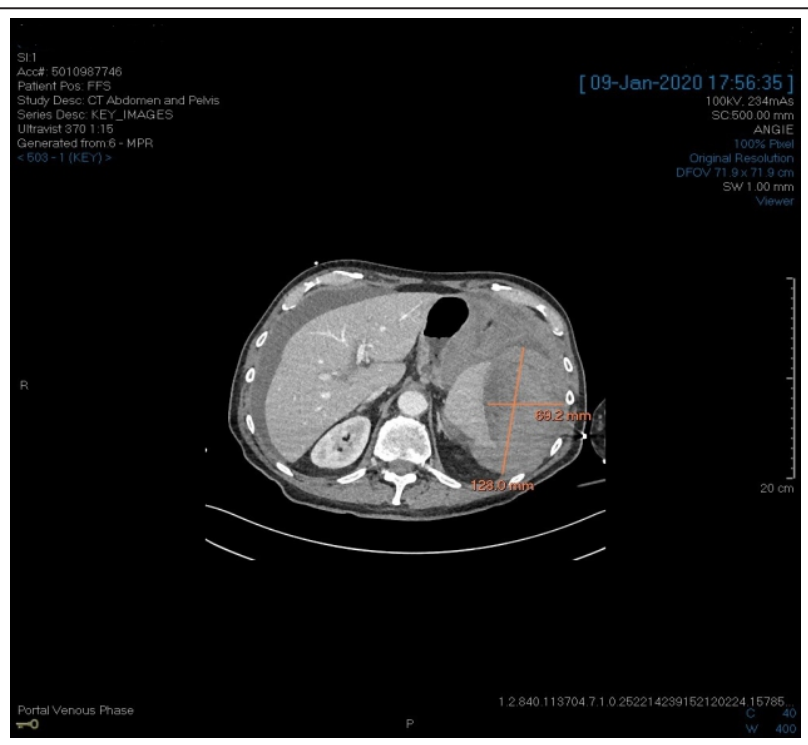

Figure 1: Transverse section of CT abdomen showing splenic rupture

in the differential diagnosis of abdominal pain in the absence of trauma. Perhaps, in hindsight, this was a lapse, unfortunately, rural hospitals are not equipped with imaging modalities such as a FAST (Focused Assessment by Sonography in Trauma) scan to make point of care diagnosis. The patient was expeditiously retrieved and a CT abdomen \& pelvis was done on arrival at the referral centre, this investigation revealed atraumatic splenic rupture associated with large peri splenic hematoma and hemoperitoneum. (Fig. 2 and 3) There weren't any other findings like mesenteric ischemia or any retroperitoneal bleed.

The patient required tranexamic acid, three units of $P R B C$ and high nor adrenaline requirement during the transfer by retrieval team. Following the imaging study, the patient was straightaway transferred to OR for an emergency exploratory laparotomy and splenectomy. The patient was admitted to ICU following the surgery for close observation and was transferred to the ward the next day. Because of atraumatic splenic rupture further workup was

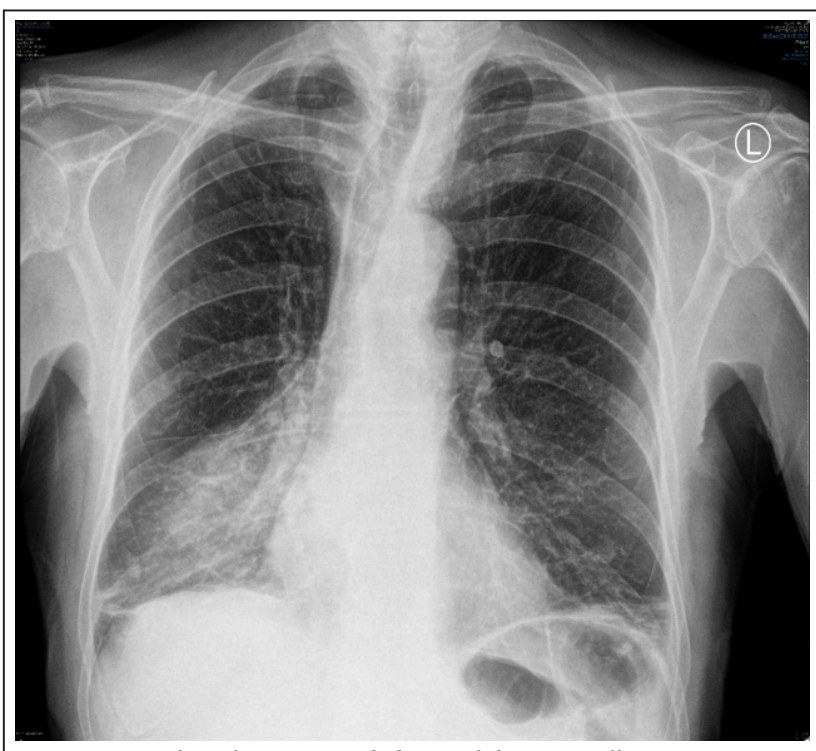

Figure 2: XR Chest showing Rt-sided Lower lobe Legionella Pneumonia done by the general medicine including haematology consultation who suggested to check paraprotein, serum-free light chains, BCRABL, JAK2, CALR and MPL. Splenic biopsy was not considered as it was considered to have a low diagnostic and therapeutic yield and wouldn't have altered the management in the absence of myelofibrosis Since all these tests were negative the possible diagnosis of spontaneous rupture of the spleen associated with Legionnaire's disease was made which was in alignment with the initial clinical suspicion by our duty intensivist.

\section{Discussion}

In MEDLINE Search, spontaneous rupture of the spleen associated with Legionnaires' disease are sparse. Table 1 summarizes the clinical characteristics of these patients and our patient. In previous cases, spontaneous rupture of the spleen occurred at a mean of 4 days (range 0 to 11 days) after the onset of symptoms. However, in our patient, the rupture of the spleen had a delayed presentation. Also, there were no symptoms to account for chronicity at this point in time. One patient died; this death was related to haemorrhagic shock [3]. Legionnaires' disease, even in severe cases, may occur in previously healthy subjects without predisposing factors [6]. Legionella can cause both community and nosocomial pneumonia. The data suggest that a delay in starting appropriate therapy for Legionella pneumonia may significantly increase the mortality [7]. However, pneumonia caused by L pneumophila cannot be differentiated from other types of pneumonia by clinical, radiographic or laboratory findings $[6,8]$. In our patient, the patient was identified to have Legionella pneumonia using urine antigen testing. PCR testing was not readily available in our laboratory. It has been a matter of standard operating procedure in our unit to do urine antigen testing as it was considered highly sensitive to legionella pneumphila type 1 in $80 \%$ cases. Given that the majority of legionnaires disease were caused by this species and not by Legionella longbeachae, it was considered appropriate to proceed with urinary antigen testing. The mechanism of spontaneous rupture of the spleen associated

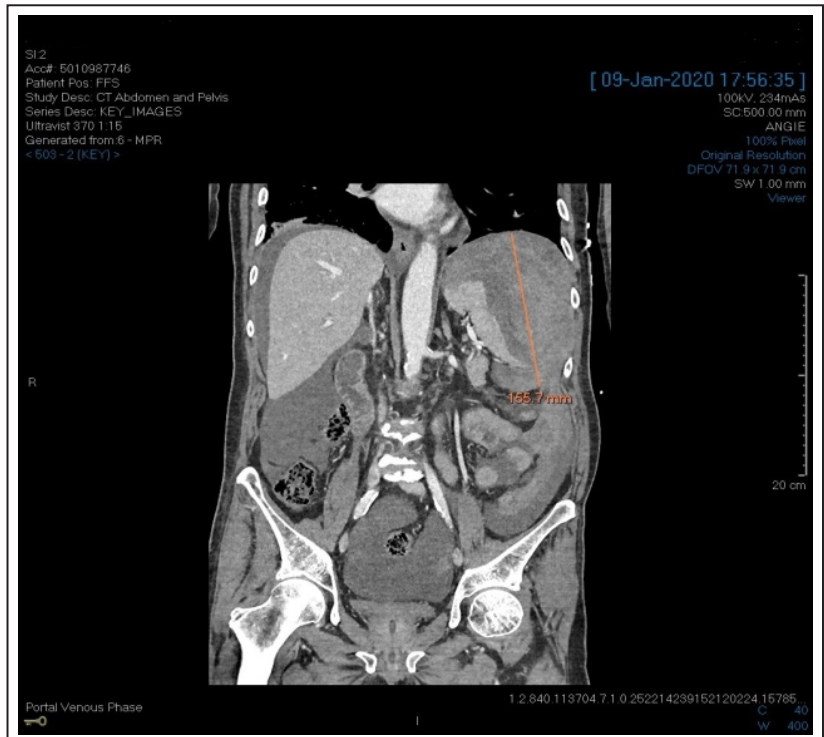

Figure 3: Coronal Section of CT Abdomen showing splenic rupture 


\begin{tabular}{|c|c|c|c|c|c|c|c|c|}
\hline Year & $\begin{array}{c}\text { Age (Yrs) } \\
\text { Sex }\end{array}$ & Underlying condition & $\begin{array}{l}\text { Location of } \\
\text { pneumonia }\end{array}$ & $\begin{array}{l}\text { Interval between initial } \\
\text { pneumonia and rupture, } \\
\text { in days }\end{array}$ & $\begin{array}{l}\text { Antibiotic } \\
\text { therapy }\end{array}$ & $\begin{array}{l}\text { Complications before } \\
\text { spleen rupture }\end{array}$ & $\begin{array}{c}\text { Spleen } \\
\text { pathology }\end{array}$ & Outcome \\
\hline \multirow[t]{2}{*}{$1990(3)$} & $63 / \mathrm{M}$ & None & Left side & 11 & $\begin{array}{l}\text { Erythromycin }+ \\
\text { Rifampicin }\end{array}$ & Liver failure, & $\begin{array}{l}\text { Enlarged, } \\
\text { soft }\end{array}$ & Died \\
\hline & & & & & & Renal failure & & \\
\hline 1993(4) & $42 / \mathrm{M}$ & $\begin{array}{c}\text { Moderate tobacco and } \\
\text { alcohol use }\end{array}$ & Left basal & 4 & $\begin{array}{l}\text { Cefotaxime+ } \\
\text { Erythromycin }\end{array}$ & None & Enlarged & Survived \\
\hline $1996(5)$ & $52 / \mathrm{M}$ & None & Left upper lobe & 5 & $\begin{array}{l}\text { Cefotaxime+ } \\
\text { Erythromycin }\end{array}$ & None & $\begin{array}{l}\text { Enlarged, } \\
\text { Splenitis }\end{array}$ & Survived \\
\hline $2008(10)$ & $47 / \mathrm{M}$ & None & Rt upper lobe & 0 & $\begin{array}{l}\text { Clarithromycin } \\
\text { +Levofloxacin }\end{array}$ & None & $\begin{array}{l}\text { Enlarged, } \\
\text { splenitis }\end{array}$ & Survived \\
\hline $\begin{array}{l}2020 \\
\text { (Current } \\
\text { Case) }\end{array}$ & $69 / \mathrm{M}$ & $\begin{array}{l}\text { Smoker, Hypertension, } \\
\text { Methotrexate } \\
\text { immunosuppression for } \\
\text { undefined arthritis }\end{array}$ & Rt Lower lobe & 21 & $\begin{array}{l}\text { Clarithromycin } \\
\text { Levofloxacin }\end{array}$ & None & $\begin{array}{l}\text { Enlarged, } \\
\text { splenitis }\end{array}$ & Survived \\
\hline
\end{tabular}

with Legionnaires' disease remains uncertain, but causes are several combinations of factors, particularly splenic distension, infection, and thrombosis $[1,5,9]$. A sudden increase in portal pressure, especially by coughing, vomiting or defecation may precipitate splenic congestion and rupture.

It has been suggested that the spontaneous rupture of the spleen should be suspected in patients admitted with Legionella pneumonia who suddenly develop clinical symptoms consistent with hypovolemic shock and failing haemoglobin levels. In our case the spontaneous rupture of spleen did not happen in the same admission but after the discharge of the patient from the hospital. The importance of the early suspicion of the rupture of spleen even after 3-4 weeks after legionella pneumonia and maybe even after months cannot be underestimated. A possible hypothesis is that the congestion of the spleen of the patient might take weeks or months to resolve. Definitive diagnosis requires investigations by ultrasonography, CT Scan and radionuclide scanning. In our case, as the patient initially presented at the rural hospital with limited facilities for advanced imaging studies, confounded by other possible differentials (i.e. sepsis and cardiogenic shock). A bed side ultrasound would have demonstrated free fluid in the peritoneum and could have expedited therapeutic intervention without needing additional imaging studies. Unfortunately, as haemorrhagic shock was not considered in the initial different diagnoses, this was a missed opportunity. Fortuitously, it was only after the discussion with senior intensivist at our hospital, consideration of the spontaneous rupture of the spleen causing haemorrhagic/hypovolemic shock was considered by the physicians of the rural hospital. There is significant distance between tertiary hospital in the cities and rural Australia and importantly the access of these quaternary facilities is dependent on emergency medical retrieval services. Any further delay in the diagnosis could have been fatal. Treatment of spontaneous rupture of the spleen associated with Legionella pneumonia should be an urgent laparotomy with splenectomy, which in most cases should be undertaken without delay as it can be life-threatening.

\section{Conclusion}

Spontaneous rupture of the spleen is a rare and life-threatening complication that should be borne in mind in patients with Legionella pneumonia even after weeks or months who present with isolated abdominal pain, circulatory shock and low or failing haemoglobin levels. When accurately diagnosed and treated in a time-critical manner, the outcome of these patients is favorable and any delay in diagnosis and subsequent intervention can be life threatening.

Declaration of patient consent: The authors certify that they have obtained all appropriate patient consent forms. In the form, the patient has given his consent for his images and other clinical information to be reported in the Journal. The patient understands that his name and initials will not be published, and due efforts will be made to conceal his identity, but anonymity cannot be guaranteed.

\section{Conflict of interest: Nil Source of support: None}




\section{References}

1. Hyun BM, Varga CF, Rubin RJ. Spontaneous and pathologic rupture of the spleen. Arch Surg 1972; 104:652-7.

2. Brown RB. Legionella pneumonia: The spectrum continues to expand. Chest 2004; 125:1979-80.

3. Holmes AH, Ng VW, Fogarty P. Spontaneous rupture of the spleen in Legionnaires' disease. Postgrad MedJ 1990; 66:876-7.

4. Saura P, Valles J, Jubert P, Ormaza J, Segura F. Spontaneous rupture of the spleen in a patient with legionellosis. Clin Infec Dis 1993; 17:298.

5. Domingo P, Rodríguez P, Lopez-Contreras J, Rebasa P, Mota S, Matias-Guiu X. Spontaneous rupture of the spleen associated with pneumonia. Eur J Clin Microbiol Infect Dis 1996; 15:733-6.

6. Roig J, Rello J, Yue VL. Légionnaires' disease : A guide to diagnosis and therapy.J Respir Dis 2002; 23:229-34.
7. Heath GH, Grove DI, Looke DFM. Delay in appropriate therapy of Legionella pneumonia associated with increase in mortality. Eur J Clin Microb Infect Dis $1996 ; 15: 286-90$

8. Gupta SK, Imperiale TF, Sarosi GA. Evaluation of the Winthrop University Hospital criteria to identify Legionella pneumonia. Chest 2001; 120:1064-71.

9. Weisenburger DD, Helms CM, Renner ED. Sporadic Legionnaires' disease. A pathologic study of 23 fatal cases. Arch Pathol Lab Med 1981; 105:130-7.

10. M Casnova-Roman, J Casas, A samchez-Porto, B Nacle. Spontaneous rupture of the spleen associated with Legionella Pneumonia. Can J Infect Dis Med Microbiol201;21(3): e107-e108.

\section{How to Cite this Article}

Yadav N, Sundararajan K | It's never too late- spontaneous rupture of spleen and lifethreatening hypovolemic shock in a patient recuperating from legionnaire's disease Journal of Anaesthesia and Critical Care Case Reports | May-August 2021; 7(2): 06-09. 